\title{
Obtaining the retainer for waterproofing road bitumens
}

\author{
Evgeniy V. Boev* (D), Aigul A. Islamutdinova iD, Elmira K. Aminova (iD \\ Branch of Ufa State Petroleum Technological University in Sterlitamak, Sterlitamak, Russia \\ * Corresponding author: e-mail: k.elmira.k@yandex.ru
}

\begin{abstract}
Introduction. Bitumen is a mixture of hydrocarbons and hetero-organic compounds. It is one of the most popular building materials today. Due to the growing consumption of bitumen for various purposes, the requirements for its quality characteristics are increasing, which prompts a comprehensive study of the physical and mechanical properties and methods of its modification. Currently, various additives are used, from inorganic materials to organic binders, including waste chemical, petrochemical and household industries. These additives create a nanodispersed structure inside the bitumen, which provides a change in the physical and mechanical properties in the required direction. Methods and materials. The work proposes a method for obtaining a fixer for waterproofing road bitumen based on nitrogen-containing organic compounds. The goal of research is to study the effect of the additive-derivative of triethylenediaminedicyan, which leads to the formation of a nanodispersed structure of bitumen of the "sol-gel" type, the quality indicators of which will meet the requirements of the new standard GOST 33133-2014 "Viscous road oil bitumen". The object of the study is the bitumen production unit of workshop No. 14 of Gazprom neftekhimSalavat LLC, designed to produce commercial bitumen: oil road grades CB 90/130 in accordance with GOST 22245-90, used in road, civil and industrial construction as a binder and waterproofing material. Results and discussion. In the course of the study, the nature of the interaction and the effect of the modifier on the properties of bitumen, which ensure the production of nanostructured bitumen of the "sol-gel" type, were revealed. As a result of the study, a comparative assessment of the effect of the fixer on the properties of waterproofing bitumen revealed a significant improvement in physical and mechanical properties in comparison with bitumen grade CB 90/130. Conclusion. The obtained compound based on triethylenediaminedicyancan can be used as a fixing additive to road bitumen.

KEYWORDS: bitumen, tar, asphaltenes, oils, dicyandiammonium compounds, nanodispersed systems, fixing additive, physicochemical properties.
\end{abstract}

FOR CITATION: Boev E.V., Islamutdinova A.A., Aminova E.K. Obtaining the retainer for waterproofing road bitumens. Nanotechnologies in Construction. 2021; 13(5): 319-327. https://doi.org/10.15828/2075-8545-2021-13-5-319-327

\section{INTRODUCTION}

$\mathrm{T}$ he use of high quality petroleum bitumen ensures the durability of asphalt concrete pavements in conditions of heavy traffic. The quality of bitumen as oil dispersed systems is directly related to their structure and properties, which are determined by the quantitative ratio of oils, resins and asphaltenes [1-3]. These three main structural elements of bituminous binders interact with each other and form one or another kind of microheterogeneousnanodispersed structure [4-6].

The physical and mechanical properties of bitumen depend on the production technology and the nature of the feedstock. The raw material source for obtaining bitumen for various purposes is the residual products of oil refining. As practice shows, these residues are subjected to all kinds of modification methods in order to give them high quality characteristics. In connection with the increase in the pace of construction in our country, the consumption of bitumen continues to grow, so the production and improvement of their quality characteristics is relevant $[7,8]$.

Modification of bitumen contributes to the expansion of the temperature range of operability, increased heat and frost resistance, ensuring the reliability and durability of structures.

Obtaining high-melting bitumen by oxidizing raw materials does not allow achieving results in terms of quality that meet the requirements of GOST. Therefore, compounding is the most optimal method. To create highmelting compositions, it is necessary to select certain additives that act as astringents. Therefore, the first stage

(c) Boev E.V., Islamutdinova A.A., Aminova E.K., 2021 
of the work was the study of the process of obtaining a binder additive [9-11].

\section{METHODS AND MATERIALS}

A method of obtaining a waterproofing composition by mixing bitumen, polymer additives and plasticizers, characterized in that the process takes place in mild conditions, the resulting bitumen is resistant at temperatures from minus 20 to plus $80^{\circ} \mathrm{C}$. Known modifications with isoprene copolymers, oligomerizates. With the addition of binders, no more than $5-7 \%$ of $100 \%$ by weight of the waterproofing composition.

To increase adhesion, mastic is used, it additionally contains waste from the production of butadiene-styrene latex, with the following ratio of components, $\%$ wt.: bitumen $20-25 \%$, asbestos $20-25 \%$, waste from the production of butadiene-styrene latex $3-15 \%$, sulfur sludge $2.0-5.5 \%$, water - the rest. Various copolymers are used for modification that increase plasticity, reducing water absorption in the ratio of \% wt: oil hydrocarbons 55-63\%, resins $12-15 \%$, asphaltenes $25-30 \%$, and as an additive - atactic polypropylene or a concentrate of rubber isoprenes with bitumen in ratio 1:1 at the following ratio, $\%$ wt.: oxidized residue of atmospheric distillation of oil 85-95\%, polymer additive 5-15\%.

Bituminous-latex emulsion composition containing bitumen, an emulsifier based on sulfonal and synthetic fatty acids, which increases weather resistance, at the following ratio, wt $\%$ : bitumen $100 \%$, vat residue of synthetic fatty acids $1-2 \%$, emulsifier $2.8-5.1 \%$, synthetic latex $65-70 \%, 45-48 \%$ solution of lignosulfonates $2-4 \%$, hexamethyldisilazane $2-4 \%$, water $55-65 \%$.

In the work of obtaining a composition for waterproofing, the filler is polyethylene, a plasticizer, extracts (waste after selective purification of distillate oils, asbestos and polypropylene glycol. This composition is distinguished by high atmospheric resistance, the following ratio of components, wt $\%$ : polyethylene $1.0-2.2 \%$, asbestos $17-30 \%$, extract $3.0-5.5 \%$, propylene glycol $0.2-1.5 \%$, bitumen - the rest.

Bituminous composition for roofing and waterproofing materials, containing bitumen and a mineral filler, characterized in that in order to increase the biostability of the composition, as a filler it contains a cake of copper smelting production, with the following ratio of components, wt $\%$ : bitumen $75-90 \%$, cake $10-25 \%$.

It is known that styrene-butadiene rubbers are part of the bitumen as a binder. Their use makes it possible to improve the technical characteristics of the product, fillers for bitumen - asbestos, white spirit, rubber (styrene butadiene), oil (automobile) [12-14].

In order to increase the weather resistance, add to bitumen: polyethylene, oil (automobile), oligovinylethanolamine, talcomagnesite.
A method of obtaining waterproofing mastic. Mastic contains $39-99 \%$ wt oxidized bitumen and 1-8\% oxidized polyethylene. To regulate the viscosity, up to $40 \%$ of a saturating substance is introduced into its composition - not oxidized bitumen. Mastics containing 71-89\% of oxidized bitumen, $1-4 \%$ of polyethylene and $10-25 \%$ of a saturating substance have optimal properties; $50-60 \%$ of mineral chips are used as a filler. The mastic is prepared by adding oxidized bitumen to oxidized polyethylene. Polyethylene, molecular weight $-2000-6000$, softening point $130-1500^{\circ} \mathrm{C}$, Brookfield viscosity at $149^{\circ} \mathrm{C} 5000-30000 \mathrm{cP}$.

A waterproofing composition comprising bitumen, a thermoplastic copolymer of ethylene, propylene, ethylidene, characterized in that, in order to increase biostability, it contains a filler such as ash, asbestos, fiberglass, polymer fibers, soot of silicate or carbonate mineral powders, with the following composition ratio, wt $\%$.: bitumen $20 \%$, ternary copolymer and polyethylene $20 \%$, filler $60 \%$ (polyethylene content is equal to $0.3 \%$ by weight of the ternary copolymer weight).

The method of obtaining a bitumen composition for priming steel pipes, which allows to increase the stability of the material, is used as a binder CPL (50:50). It is prepared by mixing at $200^{\circ} \mathrm{C}$ for 2 hours a mixture with the following content of components, wt $\%$ : bitumen $45 \%$, a mixture of CPL 42\%, 2-methyl-1-butene and 3-methyl1-butene $42 \%$, high density polyethylene $5 \%$, isobutyl rubber $5 \%$, epoxy $5 \%$. Theflowcoatinghasahightearstrength.

Waterproofing material made of polymer bitumen, characterized in that the cover layer consists of a mixture of bitumen (penetration 70-420*0.1 mm, softening temperature $20-50^{\circ} \mathrm{C}, 10-30 \%$ homo- and copolymers based on atactic polypropylene, 5-20\% isotactic polypropylene (melt index 20-40). The outer surface of the cover layer contains polypropylene crystals in the form of spherulites, which improve adhesion and prevent oil components from sweating out of bitumen.

Bitumen at a temperature of $160-200^{\circ} \mathrm{C}$ is mixed with polymers, the mixture is homogenized under high gravity, at $180-200^{\circ} \mathrm{C}$ it is cast in the form of a film and cooled at a rate of $120 \mathrm{~K} / \mathrm{min}$.

Waterproofing composition, characterized in that in order to increase the adhesion to concrete and metal, as well as to increase the temperature range, add to bitumen: polypropylene and plasticizers filtration waste. The sludge contains $30-50 \%$ dialkyl phthalates, $2-7 \%$ sodium salts of monoesters of phthalic acid, the rest is activated carbon. The proposed composition has a softening temperature by ring-and-ball method $92-100^{\circ} \mathrm{C}$, heat resistance $85-95^{\circ} \mathrm{C}$, adhesion to concrete and metal, respectively, $0.61-0.86$ and $0.7-0.9 \mathrm{MPa}$, water absorption $0.8-0.83 \%$.

Currently, many researchers make a great contribution to the selection of effective fillers, binders, etc., in order to impart crack resistance, strength, adhesion and other 
performance characteristics to bitumen in various climatic conditions [15]. When studying reagents that meet the requirements of GOST, we were guided by the operating conditions of the material and the design of the reaction unit, as well as climatic influences (Table 1).

These properties were the main criteria when choosing polymer additives for bitumen.

By the nature of the effect on bitumen, polyethylene and EPC belong to additives that change the structure of the product. Table 2 shows the composition of mastics based on polymer additives to bitumen.

Currently, there are GOSTs for bitumen, which are used as insulating bitumen. The characteristics of insulating bitumen are given in table 4 [16-17].

Synthesis of dicyandiammine is carried out in a reactor, which is a four-necked round-bottom flask equipped with a stirrer, thermometer, glycerin bath, separating funnel, reflux condenser, thermostat. $46 \mathrm{~g}$ of ethylenediamineare poured into the reactor, the temperature in the reactor is brought to $30^{\circ} \mathrm{C}$ and $0.23 \mathrm{~g}$ of the catalyst is tetraethylammoniumethoxide (alcohol solution). With stirring, $106.0 \mathrm{~g}$ of propenenitrile (acrylonitrile) is added dropwise to the reactor through a separating funnel and the mixture is stirred for two hours.

The reaction of the synthesis of triethylenediaminedicyan:

$$
\begin{aligned}
& 2 \mathrm{CH}_{2}=\mathrm{CH}-\mathrm{C} \equiv \mathrm{N}+\mathrm{H}_{2} \mathrm{NCH}_{2}-\mathrm{CH}_{2}-\mathrm{NH}_{2}+ \\
& +\left[\left(\mathrm{C}_{2} \mathrm{H}_{5}\right)_{4} \mathrm{~N}^{+} \cdot \mathrm{O}^{-}\left(\mathrm{C}_{2} \mathrm{H}_{5}\right) \rightarrow\right. \\
& \mathrm{N} \equiv \mathrm{C}-\mathrm{CH}_{2}-\mathrm{CH}_{2}-\mathrm{HN}-\mathrm{CH}_{2}-\mathrm{CH}_{2}-\mathrm{NH}- \\
& -\mathrm{CH}_{2}-\mathrm{CH}_{2}-\mathrm{C} \equiv \mathrm{N}
\end{aligned}
$$

Next, a solution of methanal ( $37 \%$ aqueous solution) was added to the reaction mixture, in a molar ratio to ethylenediamine equal to $1: 2$. At a temperature of $30^{\circ} \mathrm{C}$, the mixture is stirred for two hours to obtain a compound of structure:

\begin{tabular}{|c|c|c|c|c|}
\hline Materialproperties & $\begin{array}{l}\text { Hydraulic- } \\
\text { structures }\end{array}$ & $\begin{array}{c}\text { Overground } \\
\text { structures }\end{array}$ & $\begin{array}{l}\text { Underground } \\
\text { structures }\end{array}$ & Roofs \\
\hline Waterabsorption, \%wt. & 1.0 & 3.0 & 1.5 & 5.0 \\
\hline Swelling, \%vol. & 0.5 & 1.0 & 0.8 & 1.5 \\
\hline Heat resistance, not less, ${ }^{\circ} \mathrm{C}$ & +40 & +60 & +40 & +70 \\
\hline Brittlenesstemperature, ${ }^{\circ} \mathrm{C}$ & -15 & -40 & -5 & -50 \\
\hline Tensile strength at break, N/m, MPa & 1.0 & 0,8 & 0.5 & 1,5 \\
\hline $\begin{array}{l}\text { Resistance against aggression: } \\
\text { - Total acid, pH, less } \\
\text { - Alkaline, g/l } \\
\text { - Sulfate, mg/l }\end{array}$ & $\begin{array}{c}5.0 \\
80 \\
2000\end{array}$ & $\begin{array}{c}4.0 \\
100 \\
5000\end{array}$ & $\begin{array}{c}4.0 \\
150 \\
2000\end{array}$ & $\begin{array}{c}6.5 \\
50 \\
1000\end{array}$ \\
\hline Decrease in elongation after $500 \mathrm{~h}, \%$ & 25 & 10 & 30 & 5 \\
\hline Minimumdurability, years & 50 & 10 & 50 & 10 \\
\hline
\end{tabular}

$$
\begin{aligned}
& \mathrm{N} \equiv \mathrm{C}-\mathrm{CH}_{2}-\mathrm{CH}_{2}-\mathrm{N}\left(\mathrm{CH}_{2} \mathrm{OH}\right)-\mathrm{CH}_{2}- \\
& -\mathrm{CH}_{2}-\mathrm{N}\left(\mathrm{CH}_{2} \mathrm{OH}\right)-\mathrm{CH}_{2}-\mathrm{CH}_{2}-\mathrm{C} \equiv \mathrm{N} .
\end{aligned}
$$

\section{Table 1}

\section{Basic technical requirements for waterproofing various structures}

\section{Table 2}

Composition of mastics (polymer-bitumen), wt\%

\begin{tabular}{|l|c|c|c|}
\hline \multicolumn{1}{|c|}{ Component } & Bitudien-3 & Bitudien-L & Bitulen-90 \\
\hline Powderedpolyethylene & - & - & 3 \\
\hline Polydiene & 20 & 20 & - \\
\hline $\begin{array}{l}\text { Petroleumbitumens for insulation } \\
\text { of oil-and-gas pipelines: }\end{array}$ & & & 97 \\
- BPI-IV & - & - & - \\
- BPI-V & 80 & 80 & \\
\hline
\end{tabular}


Table 3

Main technical properties of bitumen-polymer mastics

\begin{tabular}{|c|c|c|c|c|c|}
\hline Mastic & $\begin{array}{c}\text { SPby ring-and- } \\
\text { ball method, K, } \\
\text { not less }\end{array}$ & $\begin{array}{c}\text { Elongation, } \\
\mathbf{c m}, \text { notless }\end{array}$ & $\begin{array}{c}\text { Penetration, } \\
\mathbf{1 0} \mathbf{~ m m ,} \\
\text { not less }\end{array}$ & $\begin{array}{c}\text { Maximum tempera- } \\
\text { ture of the transported } \\
\text { product, K }\end{array}$ & $\begin{array}{c}\text { Permissible ambient } \\
\text { temperature when } \\
\text { applying mastic, K }\end{array}$ \\
\hline Bitudien 3 & 343 & 4 & 30 & 293 & $253-278$ \\
\hline Bitudien-L & 363 & 3 & 20 & 308 & $263-303$ \\
\hline Bitulen-90 & 363 & 2 & 15 & 308 & $268-308$ \\
\hline
\end{tabular}

\section{Table 4}

\section{Characteristics of insulating bitumen GOST 9812-61}

\begin{tabular}{|c|c|c|c|}
\hline \multirow{2}{*}{ Indicators } & \multicolumn{3}{|c|}{ Insulating } \\
\hline & BPI-IV & BPI-IV-3 & BPI-V \\
\hline 1) Penetration $_{25}, 0.1 \mathrm{~mm}$ & $25-40$ & $30-40$ & not less 20 \\
\hline 2) Elongation at $25^{\circ} \mathrm{C}, \mathrm{cm}$, notless & 4 & 4 & 2 \\
\hline 3) Softening point, ${ }^{\circ} \mathrm{C}$, notless & 75 & $65-75$ & 90 \\
\hline 4) Water resistance for 24 hours, $\%$ weight, no more & 0.2 & 0.2 & 0.2 \\
\hline $\begin{array}{l}\text { 5) Content, \%: } \\
\text { a) water-soluble compounds, no more; } \\
\text { б) asphaltogenic acids, not less; } \\
\text { в) paraffin, no more; } \\
\text { г) sulfur, nomore }\end{array}$ & $\begin{array}{c}0.2 \\
1.25 \\
- \\
-\end{array}$ & $\begin{array}{c}0.2 \\
1.25 \\
4 \\
2\end{array}$ & $\begin{array}{c}0.2 \\
1.25 \\
- \\
-\end{array}$ \\
\hline
\end{tabular}

Ethanic acid is added dropwise to the resulting compound through a separating funnel (the molar ratio of ethanic acid to ethylenediamine is $2: 1$ ). Stirring is carried out at a temperature of $30 \div 40^{\circ} \mathrm{C}$ for at least three hours.

During the study, the following methods were used:

1. Compounding of additives is the mixing of different additives in different proportions in order to improve their effect on the properties of bitumen. Additives in different mass ratios were placed in a metal container, placed on a hotplate, a stirrer was installed and stirred for 15 minutes, then the stirrer was turned off, and a sample was taken to determine various properties. After that, the stirrer was turned on, and so every 15 minutes for two hours.

2. Compounding bitumen with additive

In a metal container, $100 \mathrm{~g}$ of bitumen was taken and, depending on the ratio, the additive, a stirrer was placed there and stirred for one hour, and a sample was taken for analysis, turning off the stirrer.

3. Softening temperature according to GOST 11506-73

The temperature at which the bitumen in the ring of given dimensions softens and, moves under the weight of the ball, touches the disk of the device. Pour bitumen with some excess into two rings, which are preheated. After cooling the rings with bitumen, smoothly cut off the excess with a heated knife flush with the edges of the rings. Install a thermometer in the intermediate hole. Bitumen research is carried out in a glycerin bath at a temperature of $33-35^{\circ} \mathrm{C}$. After 10 minutes, the suspension is removed, a heated steel ball is placed with tweezers, and placed back into the bath, set so that the plane of the rings is horizontal.

For each ring and ball, we note the temperature at which the bitumen squeezed out by the ball touches the control disk of the apparatus.

4. Penetration according to GOST 11501-73. Essence - measuring the depth of penetration of the penetrometer needle into the test sample at a given load, temperature and time. We place the cup with bitumen in a bath filled with water. The water temperature in the bath should be $25^{\circ} \mathrm{C}$. The depth of penetration of the needle is determined at $25^{\circ} \mathrm{C}$ and $0^{\circ} \mathrm{C}$. Remove the cup with the sample from the bath after 60 minutes, and place it in a vessel with water with a capacity of at least 1 liter. We put the container on one hundred of laboratory installation and bring the end of the needle to the surface of the material under study so that the needle touches it slightly. We set the reading to zero, turn on the stopwatch, press the device button, allowing the needle to freely enter 
the test sample for 5 seconds. Releasing the button, write down the readings (we take measurements 3 times). The depth of penetration of the needle at $0^{\circ} \mathrm{C}$ is determined with the changes indicated below.

Pour ice water into the bath. The water temperature should be $0^{\circ} \mathrm{C}$, the sample is kept for 60 minutes.

\section{Adhesion}

Essence - to determine the adhesion of bitumen to a metal surface.

Heat $0.5 \mathrm{~g}$ of the test sample on a metal plate. Cover with another hot plate and place a weight of 500 grams on top. We make two samples. When the plates have cooled down, we apply a tensile load and write down the readings in $\mathrm{kgf} / \mathrm{cm}$.

6. Heatresistance

The essence is to determine the resistance to heat.

We weigh the plates and pour a certain amount of heated bitumen onto them. After cooling, cut off the edges and weigh the plate with bitumen.
Determine the mass of bitumen before heating $\left(\mathrm{m}_{\mathrm{bl}}\right)$. We install the plate in a vertical position in a muffle furnace and keep it at $125^{\circ} \mathrm{C}$ for 4 hours. After cooling, cut off the edges of the plate and weigh it. Determine the mass of the remaining bitumen $\left(\mathrm{m}_{\mathrm{b} 2}\right)$. Heat resistance is determined by the formula, in $\%$ :

$$
\%=\frac{m_{\tilde{\sigma 1}}-m_{\tilde{\sigma 2}}}{m_{\tilde{\sigma} 1}} \times 100 .
$$

\section{RESULTS}

When performing the experiment, the optimal synthesis parameters were selected, providing a high yield of the fixer, such as temperature, reaction time, molar ratio of reactants. The results of the experiment are shown in Figures 1-3.

According to the presented graph, as the temperature rises from $30^{\circ}$ to $40^{\circ} \mathrm{C}$, the yield of the reaction products

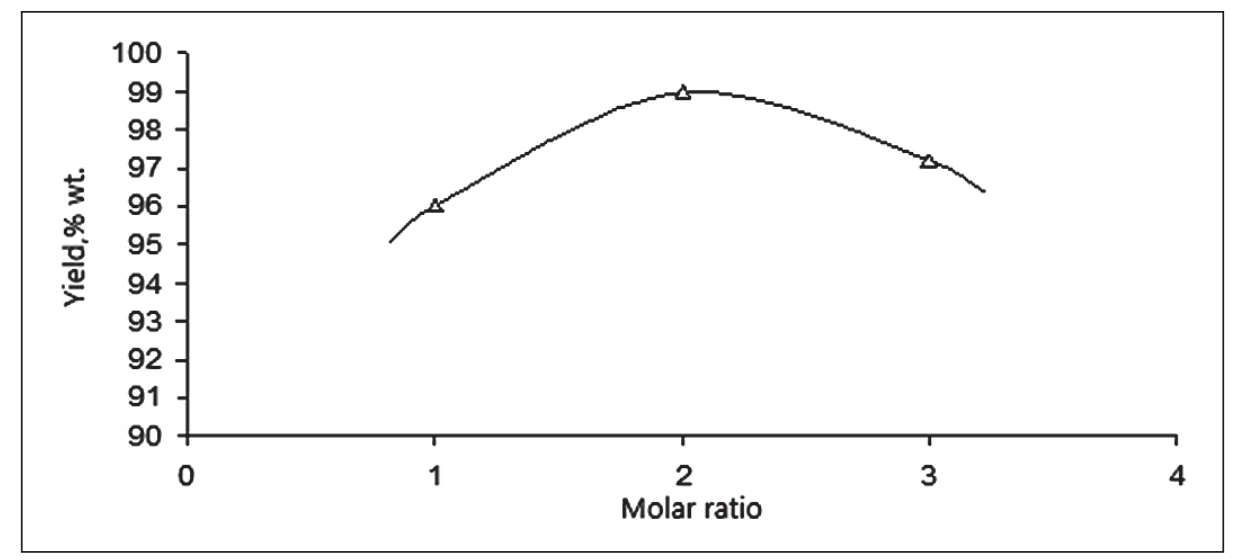

Fig. 1. Influence of the molar ratio of reactantsto the output of dicyandiammonium compound: ethylenediamine : propene nitrile : methanal : ethanoic acid $1-1,0: 2,0: 2,1: 2,0 ; 2-1,0: 2,0: 2,0: 2,0 ; 3-1,0: 2,0: 2,0: 2,1$

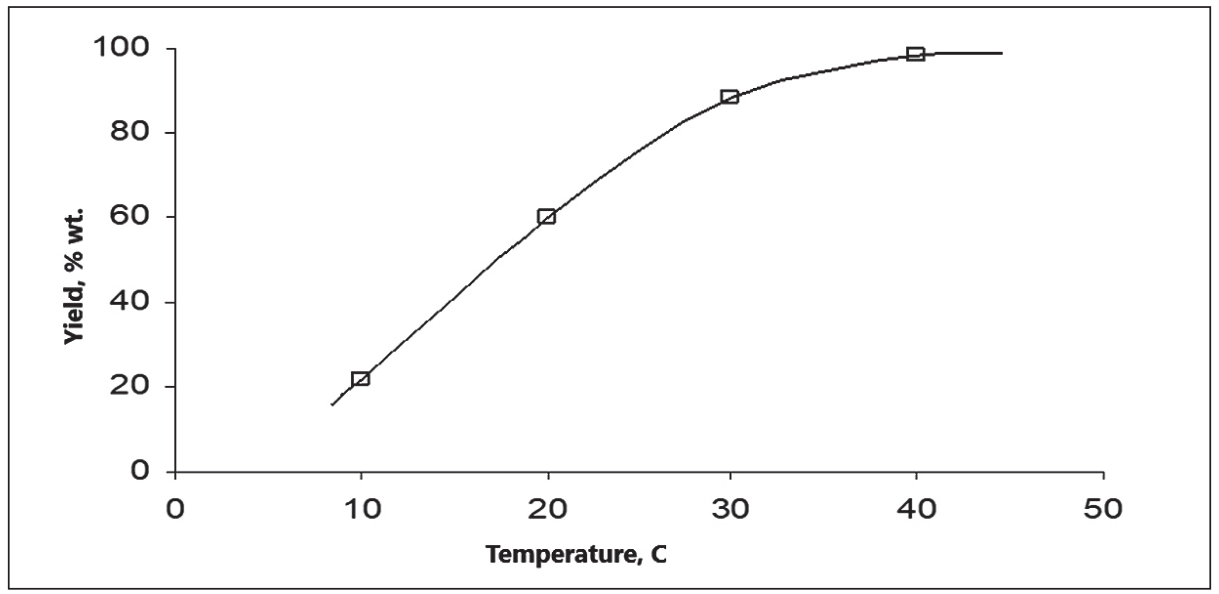

Fig. 2. Dependence of the yield of dicyandiammonium compounds from temperature (* exposure duration 0.5 hours) 


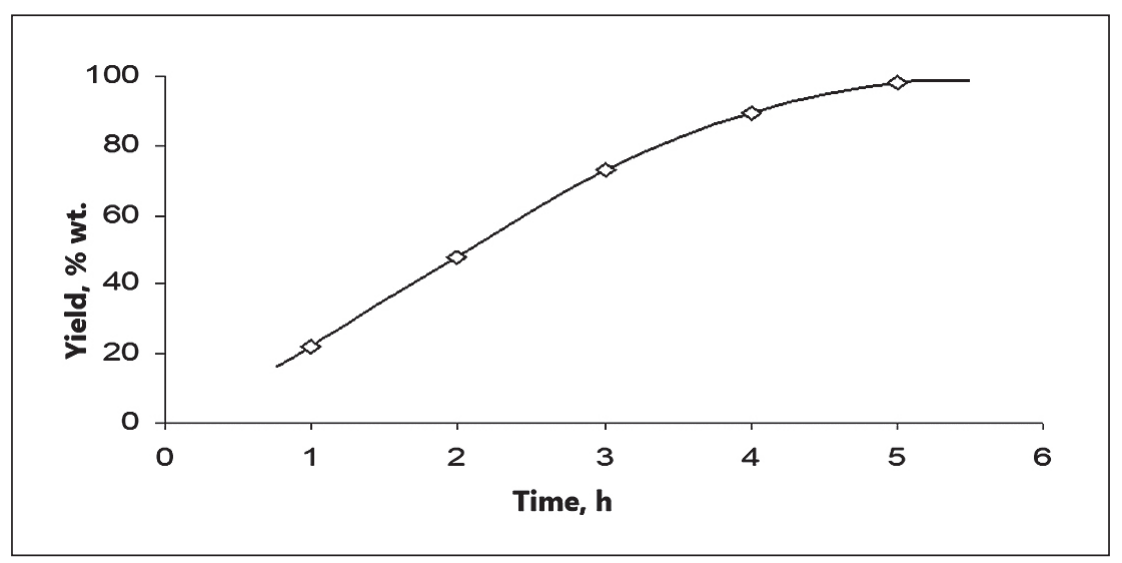

Fig. 3. Dependence of the yield of dicyandiammonium compounds onreaction time

increases. A further increase in temperature does not affect the yield of the dicyandiammonium compound.

At a temperature of $40^{\circ} \mathrm{C}$, the synthesis of the dicyandiammonium compound is completed in $5.0 \mathrm{~h}$ with a yield of the reaction product of $99.0 \% \mathrm{wt}$.

The dicyandiammonium compound obtained was identified by the elemental composition of the $\mathrm{NMR}^{1} \mathrm{~N}$ spectrum.

The obtained NMR ${ }^{1}$ Nspectra confirm the proposed structure of the synthesized dicyandiammonium compound.

At a temperature of $40^{\circ} \mathrm{C}$, the synthesis of the dicyandiammonium compound is completed in $5.0 \mathrm{~h}$ with a yield of the reaction product of $99.0 \% \mathrm{wt}$.

The obtained dicyandiammonium compound was identified by the elemental composition of the NMR ${ }^{1} \mathrm{~N}-$ spectrum, which is shown in Figure 3.13. The $\mathrm{NMR}^{1} \mathrm{~N}$ spectrum was recorded on a Bruker-AM-300 spectrometer with an operating frequency of $300 \mathrm{MHz}$, the in- ternal standard is TMS. The spectrum was recorded in deutero-acetone (D-Ac), chemical shifts were measured on the $\delta$-scale and given in ppm, and the spin-spin coupling constant (SSCC) in Hz. NMR ${ }^{1} \mathrm{~N}$ spectrum: 1.3 (s, $6 \mathrm{H}, \mathrm{CH} 3) ; 2.35$ (m, 4H, CH2); 2.63 (m, 4H, CH2); 2.73 (m, 2H, CH2); 3.05 (m, 2H, CH2); 3.72 (d, 2H, CH2, $\mathrm{J}=10) ; 3.8(\mathrm{~d}, 2 \mathrm{H}, \mathrm{CH} 2, \mathrm{~J}=10)$.

In the $\mathrm{NMR}^{1} \mathrm{~N}$ spectrum, due to the presence of symmetry in the molecule, only seven groups of peaks are observed. Intensive multiplet $2.05 \mathrm{ppm}$. is the resonance signal of the protons of the partially deuterated acetone present in the deuteroacetone. Singlet $1.3 \mathrm{ppm}$ with an integrated intensity of six protons belongs to the methyl protons of two equivalent acetate groups. In the weakest field, the multiplet is $3.72 \div 3.80 \mathrm{ppm}$. (integrated intensity - four protons), two equivalent methylene groups with nitrogen atoms and hydroxyl groups in the $\alpha$-positions resonate. Multiplet $2.35 \mathrm{ppm}$ (integrated intensity - four protons) refers to two methy-

\section{Table 5}

Physical and chemical indicators of dicyandiammine

\begin{tabular}{|l|l|}
\hline Name & Indicator \\
\hline 1. Appearance & $\begin{array}{l}\text { Syrupy mass from } \\
\text { colorless to yellow }\end{array}$ \\
\hline 2. Solubility in distilled water at $30^{\circ} \mathrm{C}$ & complete \\
\hline $\begin{array}{l}\text { 3. The relative viscosity of an aqueous solution } \\
\text { in a ratio of } 1: 1 \mathrm{vol} . \text { at } 20^{\circ} \mathrm{C}, \mathrm{cPs}\end{array}$ & 1.480 \\
\hline 4. Density at $20^{\circ} \mathrm{C}, \mathrm{g} / \mathrm{cm}^{3}$ & 1.0800 \\
\hline 5. pH & 7.0 \\
\hline 6. Acidity, $\mathrm{mg} \mathrm{KOH}$ & 19.1 \\
\hline $\begin{array}{l}\text { 7. Stability, } \mathrm{rpm} \\
(3000 \mathrm{rpm}, \tau=15 \mathrm{~min} .)\end{array}$ & $\begin{array}{l}\text { Resilient } \\
(\text { does not delaminate) }\end{array}$ \\
\hline 8. Mass fraction of nitrogen, $\% \mathrm{wt}$. & 15.0 \\
\hline
\end{tabular}


lene groups at $\mathrm{C} \equiv \mathrm{N}-$ group.The other three groups of peaks $2.63 \mathrm{ppm}, 2.73 \mathrm{ppm}$. and $3.05 \mathrm{ppm}$. belong to four $\mathrm{CH}_{2}$-groups at nitrogen atoms (the integrated intensity corresponds to eight protons).

The obtained NMR ${ }^{1}$ Nspectra confirm the proposed structure of the synthesized dicyandiammonium compound.

The physicochemical parameters of the dicyandiammonium compound are shown in Table 5.

The dicyandiammine synthesized by us has high efficiency when added to bitumen as a fixing agent, is environmentally safe during its synthesis and practical use due to the complete binding of free ethanic acid and methanal in the complex.

\section{DISCUSSION}

It follows from the literature review that at present the production of nitrogen-containing compounds is used in many areas of industry.

The current stage of development of the petrochemical industry is currently focused on obtaining products of the main organic and petrochemical synthesis with high technical and operational characteristics.
In this direction, diamines are of scientific and practical interest, as the practical experience of their use confirms, they provide protection of polymer compounds from abrasion, aging, exposure to an aggressive environment, improve their physical and mechanical properties, and have a long service life.

In order to study the effect of the modifier (fixer) synthesized by us on bitumen, the following methods of analysis were carried out: penetration, softening temperature (ring-and-ball method).

An increase in the concentration of the fixer in the test samples did not lead to its stratification with bitumen, which indicates their compatibility. The experimental results are shown in table 6.

The presented data indicate an increase in the penetration index with an increase in the mass fraction of dicyandiamine. That is, an excessive increase in the content of dicyandiamine leads to a decrease in the hardness of the samples, which indicates a decrease in the value of such an indicator as surface tension.

Measurements of the softening point (using the ringand-ball method) showed that with an increase in the content of the fixer, an increase in the softening temperature occurs, which means that the modified samples

\section{Table 6}

Dependence of indicators on the concentration of the modifier

\begin{tabular}{|l|c|c|}
\hline \multirow{2}{*}{\multicolumn{1}{|c|}{ Nameofsamples }} & \multicolumn{2}{c|}{ Qualitativeindicators } \\
\cline { 2 - 3 } & Penetration, $\mathbf{~ m m}$ & Temperature softening (Ts), ${ }^{\circ} \mathbf{C}$ \\
\hline Initialbitumen & 3.1 & 95 \\
\hline Bitumen with 10\% additive & 3.3 & 98 \\
\hline Bitumen with 20\% additive & 3.6 & 100 \\
\hline Bitumen with 30\% additive & 3.9 & 102 \\
\hline Bitumen with 40\% additive & 4 & 103 \\
\hline
\end{tabular}

Table 7

Research results at various concentrations

\begin{tabular}{|c|c|c|c|c|c|}
\hline Concentration, $\%$ & Softeningpoint, ${ }^{\circ} \mathrm{C}$ & $\begin{array}{l}\text { Penetrationat } \\
25^{\circ} \mathrm{C}, \mathrm{mm}\end{array}$ & $\begin{array}{c}\text { Penetrationat } \\
0^{\circ} \mathrm{C}, \mathrm{mm}\end{array}$ & $\begin{array}{l}\text { Adhesion, } \\
\text { kgf/cm }\end{array}$ & $\begin{array}{c}\text { Heatresistance, } \\
\%\end{array}$ \\
\hline 10 & 160 & 3.3 & 6 & 41 & 16.7 \\
\hline 20 & 163 & 3.6 & 6 & 39 & 16.0 \\
\hline 30 & 165 & 3.9 & 6.3 & 35 & 15.7 \\
\hline 40 & 167 & 4 & 6.5 & 32 & 15.0 \\
\hline 50 & 168 & \multicolumn{4}{|c|}{ Not a homogeneousmixture } \\
\hline 60 & 169 & \multicolumn{4}{|c|}{ Not a homogeneousmixture } \\
\hline
\end{tabular}


are not subject to softening at the temperature at which the initial sample softens and softens only with a further increase in temperature, and with an increase in the content of the fixer, the difference is Ts only increases.

Thus, the proposed bitumen fixer, at various ratios, gives the product elasticity and increased resistance to softening with increasing temperature.

In order to study the operational characteristics of road bitumen for its compatibility with the fixer, experiments were carried out at higher softening temperatures.

Compounding was carried out at a temperature of $210^{\circ} \mathrm{C}$ for 60 minutes. The resulting products have been tested to determine their physical and mechanical characteristics. The research results are presented in table 7 .

According to the presented data in the table, the best properties of bitumen with a modifier were found at a concentration of a fixer of $30-40 \%$ by weight.

It can also be noted that an increase in temperature contributed to an improvement in technical performance.
Characteristics of the obtained samples: homogeneous structure, high softening point and good adhesion properties. It was also observed that an increase in the content of the fixer leads to the destabilization of the dispersed structure of bitumen.

\section{CONCLUSION}

Thus, the outcome of the study is a fixative based on an additive, a derivative of triethylenediaminedicyan, which led to the formation of a nanodispersed structure of bitumen of the "sol-gel" type, the quality indicators of which would meet the requirements of the new standard GOST 33133-2014 "Viscous road oil bitumen". Its synthesis laws and physical and chemical parameters were studied, the structure was proved.

The proposed bitumen fixer, at various ratios, gives the product elasticity and increased resistance to softening with increasing temperature.

\section{REFERENCES}

1. Gun R.B. Petroleumbitumens. Moscow: Chemistry; 1983.

2. Rebinder P.A. Surface phenomena in dispersed systems. Moscow: Nauka; 1978.

3. Safieva R.Z. Physicochemistry of oil. Physical and chemical foundations of oil refining technology. Moscow: Chemistry; 1998.

4. Rudenskaya I.M., Rudensky A.V. Organic binders for road construction. Moscow: Infra-M; 2010.

5. Nelyubova V.V., Kobzev V.A., Sivalneva M.N., Podgorny I.I., PalshinaYu.V. Features of nanostructured binder depending on the genesis of raw materials. Bulletin of BSTU named by V.G. Shukhov. 2015; 2: 25-28.

6. Gotovtsev V.M., Shatunov A.G., Rumyantsev A.N., Sukhov V.D. Nanotechnology in the production of asphalt concrete. Fundamental research. 2013; 11: 191-195.

7. Grudnikov I.B. Production of petroleum bitumen. Moscow: Chemistry; 1983.

8. Tanatarov M.A. et al. Technological calculations of oil refining units. Moscow: Chemistry; 1987.

9. Ishmuratova R.T., Kalimullin L.I., A.A. Islamutdinova. Study of the effect of spent catalysts in highly oxidized road bitumen. In: Fundamental and applied research in technical sciences in the context of the transition of enterprises to import substitution: problems and solutions: Collection of materials of the All-Russian scientific and technical conference with international participation. Vol. 1. Ufa: USPTU Publishing House; 2015. p. 335-338.

10. Ishmuratova RT, Islamutdinova A.A. Polymer additives to waterproofing bitumen. In: Innovative technologies in industry: education, science and production: Collection of materials of the All-Russian scientific-practical conference with international participation. Ufa: Publishing house "Petroleum engineering"; 2016. p. 97-98.

11. Gurevich I.L. Oil and Gas Processing Technology. Moscow: Chemistry; 1972.

12. Pechenii B.G. Bitumen polymer and petroleum polymer compositions. Moscwo: TsNIITEneftekhim; 1992.

13. Sardanashvilli A.G. Examples and tasks for oil and gas technology. Moscow: Chemistry; 1973.

14. Rudin M.G., Drabkin A.E. Brief reference book of oil refiners. Leningrad: Chemistry; 1980.

15. Guseynov D.A. et al. Technological calculations of oil refining processes. Moscow: Chemistry; 1964.

16. Kisina A.M. etc. Polymerbituminous roofing and waterproofing materials. Leningrad: Stroyizdat; 1983.

17. Rudin M.G. Pocket reference book of oil refiner. Leningrad: Chemistry; 1989. 


\section{INFORMATION ABOUTTHE AUTHORS}

Evgeniy V. Boev - Cand. Sci. (Eng.), Associate Professor, Head of the Department of General Chemical Technology, Branch of Ufa State Petroleum Technological University in Sterlitamak, Republic of Bashkortostan, Sterlitamak, Russia, 9196011116@mail.ru, https://orcid.org/0000-0001-9255-6142

Aigul A. Islamutdinova - Cand. Sci. (Eng.), Associate Professor, Associate Professor of the Department of General Chemical Technology, Branch of Ufa State Petroleum Technological University in Sterlitamak, Republic of Bashkortostan, Sterlitamak, Russia, aygul_ru@ mail.ru, https://orcid.org/0000-0003-3104-2097

Elmira K. Aminova - Cand. Sci. (Chem.), Associate Professor, Associate Professor of the Department of General Chemical Technology, Branch of Ufa State Petroleum Technological University in Sterlitamak, Republic of Bashkortostan, Sterlitamak, Russia, k.elmira.k@ yandex.ru, https://orcid.org/0000-0002-3105-3477

\section{CONTRIBUTION OF THE AUTHORS}

The authors contributed equally to this article.

\section{The authors declare no conflicts of interests.}

The article was submitted 06.09.2021; approved after reviewing 28.09.2021; accepted for publication 04.10.2021. 